\title{
DE CARLOS EUGÊNIO À “CODINOME CLEMENTE”, ENTREVISTA COM ISA
} ALBUQUERQUE

\section{FROM CARLOS EUGENNIO TO "CODINOME CLEMENTE", INTERVIEW WITH ISA ALBUQUERQUE}

\section{Augusto SARMENTO-PANTOJA (UFPA) ${ }^{1}$ Tânia SARMENTO-PANTOJA (UFPA) ${ }^{2}$}

\begin{abstract}
Resumo: Entrevista realiza no dia 15 de outubro de 2020, como atividade do VII Seminário Internacional Literatura e Cinema de Resistência (SELCIR). A entrevista foi conduzida pelo Prof. Dr. Augusto Sarmento-Pantoja e contou com a colaboração da Profa. Dra. Tânia SarmentoPantoja e a participação da Cineasta Isa Albuquerque e pesquisadora e viúva de Carlos Eugênio, Dra. Maria Cláudia Badan Ribeiro. A seguir transcrevemos algumas passagens da entrevista de Isa Albuquerque. A entrevista na íntegra encontra-se disponível em vídeo https://www.youtube.com/watch?v=O9LQuU0pK $\underline{\mathrm{SQ}}$.
\end{abstract}

Palavras-chave: Cinema. Resistência. Censura. "Codinome Clemente".

\begin{abstract}
Interview held on October 15, 2020, as an activity of the VII International Seminar on Literature and Resistance Film (SELCIR). The interview was conducted by PhD. Augusto Sarmento-Pantoja and had the collaboration of PhD. Tânia Sarmento-Pantoja and the participation of Filmmaker Isa Albuquerque and researcher and widow of Carlos Eugênio, PhD. Maria Cláudia Badan Ribeiro. Below we transcribe some passages from the interview with Isa Albuquerque. The full interview is available on video

https://www.youtube.com/watch?v=O9LQuU0pKs Q.
\end{abstract}

Keywords: Cinema. Resistance. Censorship. "Codinome Clemente"

\footnotetext{
${ }^{1}$ Doutor em Teoria e História Literária pela UNICAMP. Professor de Literatura da Universidade Federal do Pará (UFPA), coordenador do grupo de pesquisa Estéticas, Performances e Hibridismos (ESPERHI), pesquisador do grupo Estudos de Narrativas de Resistência (NARRARES) E-mail: augustos@ufpa.br

${ }^{2}$ Doutora em Estudos Literários pela UNESP-Araraquara. Professora de Literatura Portuguesa da Universidade Federal do Pará (UFPA), coordenadora do Grupo de pesquisa Estudos de Narrativas de Resistência (NARRARES). Bolsista produtividade em pesquisa PQ-2 CNPQ.E-mail: nicama@ufpa.br
} 
Augusto Sarmento-Pantoja - Isa, bom dia! Obrigado por ter aceitado o convite para falar um pouco sobre o filme "Codinome Clemente". Par iniciar, peço que fale um pouco do seu percurso como cineasta?

Isa Albuquerque - Bom dia Augusto, vou começar falando do meu último filme, o "Ouro Negro”, que lancei em 2008 e conta a história de João Martins e a busca pelo petróleo em Alagoas. Esse filme fez o percurso completo do que era esperado de um longa-metragem como ele, um filme de porte médio. Antes disso, nós tivemos a produção do "Histórias do olhar", que realizei em 2003. O "Histórias do olhar é um longa-metragem já bastante onírico sobre o universo feminino. Esse filme foi lançado em 2003 e foi o meu primeiro longa-metragem. Agora, meu desafio consiste no lançamento do "Codinome Clemente". O filme está pronto, já foi exibido em Los Angeles, em Paris e nós estamos nesse momento, diante de uma peleja com a Agência Nacional de Cinemas (ANCINE) que é o nosso instituto de cinematografia no Brasil. E essa peleja significa o que há quatro mil projetos parados, sem andamento, desde que assumiu o novo governo e, a partir desse momento, os projetos ficaram suspensos, sem dar prosseguimento à contratação. E o nosso lançamento ficou suspenso em função desse recurso que não saiu até agora. Um recurso de contratação dos serviços, inclusive da distribuidora. Nossa distribuidora é a "2 Play", que está pronta para fazer o lançamento do filme, mas está esperando apenas a liberação dos recursos para isso. E são esses os movimentos finais desse momento. Mas foi uma grande vitória ter realizado o filme, porque ele fala de um tema difícil, que é a ditadura militar brasileira. Algo que nem toda a esquerda quer falar e a direita muito menos. Então! Foi um caminhar muito acidentado até chegar a sua realização. O filme já me consumiu oito anos. Não era para chegar a tanto tempo de dedicação, mas da produção a finalização vivemos muitas dificuldades para a efetivação do projeto. São as forças, as correlações políticas. Bom! Vamos seguir...

\section{Augusto Sarmento-Pantoja - Muito Obrigado Isa. Quais são os atuais desafios de se falar de ditadura, na atual conjuntura política?}

Isa Albuquerque - Estamos nos movendo em um terreno pantanoso! Nós estamos com um governo formado por pessoas que elogiam torturadores e negam a própria ocorrência da 
ditadura, e que passa como um trator sobre os direitos humanos. Então nós somos vistos como inimigos! Falar de Ditadura Militar é um desafio. Se esse filme tivesse sido lançado há cinco anos atrás, seria um simples resgaste de memória. Mas acaba que nós estamos trabalhando pelo lançamento do filme nesses dois anos do Governo Bolsonaro, por isso, o filme se torna uma advertência. "Olha ai o que aconteceu nos anos sessenta". "Olha aí o que nós não podemos deixar que aconteça nos próximos anos. ” Esse tipo de advertência em forma de filme, vem sendo feita por várias produções, não só pela minha. Mas essas produções precisam chegar ao público, não é? Porque é o público que forma a sua opinião, a partir daquilo que ouve e vê, daquilo que se fala a respeito de um determinado objeto de pesquisa.

\section{Augusto Sarmento-Pantoja - Como foi ter o depoimento de Carlos Eugênio?}

Isa Albuquerque - Ter o Carlos Eugênio Paz como uma testemunha viva, naquela altura, de tudo o que aconteceu, foi um grande achado dessa narrativa que fizemos, pois tínhamos alguém que podia contar de viva-voz tudo o que viveu. Poucos, realmente, tem essa capacidade de revelação ou autorrevelação como Carlos Eugênio teve. Infelizmente ele faleceu no ano passado, mas estava conosco na exibição do filme em Paris. E logo depois, cerca de um mês, ele já era acometido de um câncer e faleceu. Isso foi uma perda muito grande para a memória brasileira de uma forma geral, mas ele sempre fez questão de relatar toda a sua história através de livros também. Me confiou essa história para ser transformada nesse longa-metragem.

\section{Augusto Sarmento-Pantoja - Você acredita vivemos uma espécie de censura atualmente?}

Isa Albuquerque - Então, a dificuldade foi muito grande e a censura, dita censura, que não é, entretanto, institucionalizada, não está judicializada. Entre nós temos manifestações espontâneas, por exemplo, da atleta de vôlei da seleção brasileira que manifestou sua opinião no meio de uma live, está proibida de se manifestar novamente. Isso é censura! E nós temos também a impossibilidade concretizada na retenção do nosso recurso de lançamento, justamente conquistado através de concurso público e publicado em diário oficial. Essa retenção acontece a dois anos. Então, isso é uma forma de censura. E nós temos no Brasil 
quatro mil projetos de cinema. Não são só os filmes de viés ideológico que estão sendo combatidos, é o cinema de uma forma geral no Brasil. Por isso, esses 4 mil projetos suspensos e treze mil produtoras paralisadas e trezentos e cinquenta mil empregos por ano, cancelados! Isso se refere a uma verba, uma renda de aproximadamente dois milhões de reais movimentados pelo setor, que não estão sendo gerados agora, qual o porquê? Porque nós estamos com os recursos de fomento suspensos e toda a atividade audiovisual comprometida no Brasil. Quem ainda está trabalhando foi beneficiado com as últimas premiações em 2018. Passou que 2019 cerca de 1\% dessas produtoras conseguiu algum recurso para continuar produzindo. Nós tínhamos uma indústria produtiva, com 180 longas-metragem por ano e está paralisada, isso é censura, não é? E não é uma crise econômica, é uma crise completamente artificial, que não precisava existir, é a censura. Então é um terreno pantanoso sim, porque essa censura não é personalizada como era nos anos sessenta, quando havia o departamento de censura. Os projetos entram, e estamos movendo ações na agência para liberá-los, mas há sempre um tipo de entrave burocrático que é imposto e os projetos não andam. E isso é censura, uma censura velada! Então, estamos assim, combatendo esse tipo de autoritarismo velado que está acontecendo.

\section{Augusto Sarmento-Pantoja - $\mathbf{E}$ a atual realidade brasileira?}

Isa Albuquerque - É um momento difícil de viver no Brasil porque nós estamos vendo as nossas liberdades democráticas paulatinamente assaltadas, nós estamos vendo as nossas reservas naturais sendo destruidas e com estímulos, muitas vezes, das autoridades, não só com a omissão, mas com estímulo. Nós estamos com 150 mil mortos pela pandemia e sem um combate efetivo. É uma doença muito grave e já está vindo a nova onda na Europa, as nossas fronteiras estão fechadas, informalmente, pior seria uma guerra, que também não está longe do horizonte, mas não podemos dizer que estamos tranquilos nesse periodo que estamos vivendo. E ao mesmo tempo, lançar um filme como "Codinome Clemente", que é atual e extremamente urgente, para que se possa debater essas questões vividas, muito vívidas nesses últimos anos, nesse periodo extremamente tortuoso. Então, eu diria que é um desafio muito grande porque foi uma "guerra de guerrilhas", que é uma expressão usada pelo Carlos Marighella, o mentor do Carlos Eugênio Paz. Foi uma "guerra de guerrilhas" chegar até aqui. Então essa "guerra de guerrilhas" agora tem essa etapa, o lançamento do filme! O 
filme precisa encontrar seu público! É aí, que toda a trajetória de um filme se concretiza e se justifica! Temos que chegar lá, e pra isso nós até abrimos uma vaquinha online, para contornar essa questão financeira. Resolvendo esse problema, nós conseguiremos lançar o filme. Não sou só eu a ser prejudicada, temos um outro diretor o Wagner Moura, diretor do filme Marighella, que será lançado em abril de 2021, essa é a nova data prevista. Por isso, nós não podemos dizer que estamos livres da censura, nesse momento no Brasil, temos uma censura judicializada, uma censura velada, uma censura burocrática, é isso que estamos vivendo...

Augusto Sarmento-Pantoja - Nós estamos vivendo um Estado júri-excecional, uma espécie de exceção jurídica, em que se instaurou uma espécie de legalidade da exceção, desde o período em que houve uma grande campanha de demonização das esquerdas, e continua, não é? Ocorrendo a retirada da presidenta Dilma do poder, em um jogo jurídico muito representativo, que naquele momento, para mim, começa a se instalar esse Estado juri-excecional. Agora vamos falar um pouco mais do "Codinome Clemente". Fale um pouco sobre como surgiu a ideia de fazer esse filme. De onde veio? Como foi essa relação de fazer um filme com um personagem em vida?

Isa Albuquerque - O filme me escolheu, eu acho! Carlos Eugênio também me escolheu, como disse a Maria Cláudia. Começamos a conversar quando eu estava na produção de "Ouro Negro”, que é um épico e foi lançado em 2010. Antes, em 2004, eu fui apresentada ao Carlos Eugênio, por uma amiga em comum a Duba Elia, que é corroterista do “Ouro Negro”. A Duba me disse: "Isa, o professor de violão do meu filho tem uma história extraordinária, acho que você vai ficar fascinada com essa história e vai querer fazer um filme”. Então, a história na verdade veio para mim, ela me cercou! O certo é que quando eu conheci o Carlos Eugênio, eu achei realmente: "eu tenho muita sorte de conhecer esse personagem, esse homem gera um personagem interessantíssimo. Ele é um arquivo vivo de tudo o que foi vivido nos anos sessenta pelos movimentos de resistência armada”. Então, todos os documentários e filmes tratavam da questão da opressão, a tortura etc. Sempre dos efeitos em torno da resistência, não da resistência armada em si. Carlos Eugênio para mim era uma grande novidade... e dentro dessa narrativa... e não por acaso ele era o único que se dispunha a trabalhar com essa informação e informar claramente o que aconteceu nos bastidores da luta 
armada. Havia esse acordo tácito da própria esquerda de não abordar profundamente a luta de uma forma geral. E por conta do rompimento desse silêncio, havia uma certa "prevenção" da esquerda contra o próprio Carlos Eugênio, e, por isso, muitas vezes ele entrou em choque com as esquerdas de forma geral, porque ele rompeu esse primeiro código de silêncio. Pois bem, para mim, como documentarista, foi um privilégio conhecer o Carlos Eugênio e transformar essa história em uma narrativa cinematográfica. E como ele era muito jovem quando entrou na luta armada, ele tinha quinze, dezesseis anos! Agente não deixa criança e adolescente ir sozinhos numa festa, ele entrou na luta armada e foi acumulando um cabedal de experiências e se cercando de personagens que hoje são lendários. Ele também era uma lenda! Neste caso, o Carlos Eugênio, dentro dos movimentos de ativismo, contra a ditadura militar. Ele tem uma narrativa absolutamente original, como personagem, ele era original, representativo e simbólico. Ele simboliza toda essa luta, ele tem os atributos que eu procuro em um personagem real. Ele era um personagem sobre o qual valia a pena desenrolar um filme. E foi aí que eu fui colhendo depoimentos, chegamos a viajar par os lugares onda as lutas, onde as ações armadas aconteceram. Maria Cláudia nos acompanhou em muito desses momentos, em que eu registrava com uma câmera a narrativa dele, da forma como a coisa aconteceu, as expropriações, as ações de sequestro e tudo enfim. Essas ações foram registradas com a narrativa dele e depois transformadas em sequências de animação no filme.

\section{Augusto Sarmento-Pantoja - Porque o Cartum?}

Isa Albuquerque - Eu escolhi o Cartum como parte dessa narrativa, justamente para ilustrar esse momento que era de muito ímpeto, muito ímpeto juvenil. Ele era muito jovem, quase criança, quando ele assumiu essa luta, ficou até seis anos na luta armada, que é realmente um milagre, as pessoas morriam muito rapidamente nas mãos da repressão - os militantes em especial. De forma geral, Carlos Eugênio conseguiu escapar de todas as armadilhas graças a sua engenhosidade e as suas atitudes preventivas. E ele teve a capacidade, depois, de falar sobre todas essas ações apesar de todos e de tudo, ele foi se autorrevelando em todo o filme, com isso, nós fomos trabalhando as ações que ele foi relatando. Essa narrativa foi bastante original e justificou toda a realização dos fios. Está aí a origem de todo o processo, uma amizade, um encontro casual, alguém que pontificou esse encontro e também a disposição do 
Carlos Eugênio de me entregar a sua história para eu transformar nesse longa-metragem, que até agora está ai para ser lançado.

Tânia Sarmento-Pantoja - Isa Você enquanto mulher, de que forma o silêncio e o autoritarismo que está em seus trabalhos podem ser vistos, levando em conta o momento difícil, como esse que estamos vivendo no Brasil, em que a censura encontrou outras estratégias, outros dispositivos para se manter funcionando enquanto mecanismo repressivo e silenciador. Como vocês tem lidado com isso, para escapar desses dispositivos?

Isa Albuquerque - Bom, tem uma frase que diz que eu me identifico muito: "eu sou as minhas circunstâncias, se eu não consigo salvar as minhas circunstâncias, eu não consigo salvar a mim mesma". Pois bem! Tem sido uma luta, e para resolver e desembolar esse nó em cada etapa, em cada dificuldade, sempre há uma pedra no meio do caminho. O certo é que a nossa pedra anteriormente era o desafio de finalizar o filme, realizar a campanha de festivais, isso nós conseguimos realizar até início de 2019, já em 2020 tivemos o obstáculo da pandemia e estamos aqui nesse debate superinteressante e conhecendo essas pessoas maravilhosas como o Pantoja e a Tânia e desse lançamento, mesmo de forma virtual e tentando resolver o problema concreto da ausência de recursos para o lançamento. A nossa atividade tá paralisada efetivamente desde 2018.

Tânia Sarmento-Pantoja - Esse ataque à cultura, como você vê isso?

Isa Albuquerque - Toda a cultura está sobre ataque no Brasil, e esse ataque precisa ser rechaçado com cultura. Então é uma defesa não só da questão dos filmes mais críticos, é de tudo! Dos filmes de memória, mais também de toda a resistência da identidade cultural de uma nação, daquilo que faz um povo, uma nação, que é a sua cultura. Nós temos que defender as Universidades, essa questão da censura hoje, vem atacando, arrancando nossa possibilidade de evolução a partir da raiz, do pensamento crítico. Então! O que se quer formar atualmente? Consumidores? Não são mais cidadãos? E tem muita gente acreditando e embarcando nessa crença de que vão ser absolutamente felizes, simplesmente frequentando shopping ou comprando nas lojas. Você vê invasões imensas desses templos de consumo, absolutamente vazio. Ou os "Inocentes do Leblon", que continuam se acotovelando nos bares 
como se não existisse uma pandemia lá fora. Enfim, nosso desafio agora é lançar o "Codinome Clemente" e o nosso projeto é continua lutando pela manutenção da cultura. Atualmente eu faço parte de um movimento no Brasil chamado "Estados Gerais da Cultura", fundado pelo cineasta Silvio Tendler, que tem esse propósito. Queremos muito combater aqueles que nos combatem. Mas, o bom combate, o combate das ideias. Porque não há como esse "rolo compressor" contra a cultura ter força e sufocar a todos. A cultura é uma necessidade básica de expressão do ser humano, a cultura através do cinema, da literatura, das artes visuais, da poesia e da cultura popular. Com isso, nós pretendemos manter uma grande rede de solidariedade. Eu acho que a solidariedade universal internacional é uma grande saída para que consigamos suportar os ataques à cultura que estamos sofrendo no Brasil. Isso está acontecendo com um projeto de dominação do Brasil, mas também de toda a América Latina, você nota que há um fundamentalismo religioso ascendente, nós estamos nos transformando em uma espécie de "evangelistão”, digamos assim! Esse projeto só vai se concretizar se a cultura for vencida, mas nós vamos continuar resistindo verso a verso, filme a filme!

Tânia Sarmento-Pantoja - Uma coisa que me chamou bastante atenção quando eu assisti ao filme foi o claro confronto entre as memórias da resistência sobre o justiçamento realizado pela ALN contra o Márcio de Toledo. Como é que isso se deu, foi no processo de construção do filme, surgiu durante as gravações, já era esperado algo assim? Ou teria sido em um momento anterior, fazia parte do roteiro?

Isa Albuquerque - Era muito sensivel para o Carlos Eugênio falar sobre isso. Nós gravamos com ele pelo menos em umas dez ocasiões, talvez um pouco menos, o mesmo depoimento. Ele, em momentos diferentes da vida, foi solicitado que falasse sobre esse incidente. Acontece, que ele foi sempre muito acusado pela própria esquerda, pela direita, por tudo, a respeito desta execução que cometeu, mas porque foi uma decisão do grupo. Enfim, ele, O Carlos Eugênio, é a melhor pessoa para se defender sobre esse assunto. E em seu depoimento ele discorre muito bem sobre os motivos. Foi um ato do calor da guerra e ele estavam sobre muita pressão. Aquele companheiro (Márcio de Toledo) se mostrou como um possível fator de desequilíbrio da organização e de ameaça a todos os companheiros que tinham conexão com eles. O Carlos Eugênio sofreu muito com esse incidente, com essa execução! E passou muito tempo da vida 
dele explicando as razões daquele incidente. E quando agente levanta, nós os escritores, os nossos narradores, quando levantamos a biografia, nós temos que trazer todos as contradições de um personagem. É importante ter também aquilo que ofragiliza e aquilo que o fortalece. Então, para muitos foi um erro que o Carlos Eugênio cometeu, para outros era uma situação inevitável, pois ele tava assumindo uma ação decidida em assembleia! Era importante confrontá-lo sobre isso. Por isso, na primeira, segunda, terceira, quarta, quinta vez que nós falamos sobre isso, não rendeu um bom depoimento. No depoimento que gravamos em estúdio voltei a esse assunto e foi quando ele despojou mais as suas defesas e falou francamente, falou mais claramente como a execução aconteceu e o que representava para ele. Ai fomos trabalhando com outros depoimentos em torno deste incidente, nós vamos compondo esta imagem que ficou do Carlos Eugênio, dentro dessa ação.

\section{Tânia Sarmento-Pantoja - Neste episódio você não usou o quadrinho, por quê?}

Para mim foi importante utiliza a animação em outros momentos, porque eu achei muito mais dramático trabalhar com a própria narrativa dele sem o recurso da animação. Evidentemente, era muito mais dramático, olhar nos olhos enquanto ele falava da situação que passou... e o que o levou a desenvolver esta ação. A animação ficou para os assaltos a banco, as grandes ações de expropriação, que reconstituimos com a animação, que era uma própria marca da juventude, o quadrinho. O Cartum era uma narrativa de jovens, de garotos, que sempre gostavam de ler quadrinhos. Naquela altura, era uma manifestação cultural muito ampla, por isso, eu achei que seria interessante trabalhar com os quadrinhos, como uma forma de rejuvenescer a narrativa, já que estamos falando de memórias. Memórias se reportam a um tempo longínquo, para uma geração que não viveu aquilo. A narrativa do quadrinho trabalha com a simplificação das imagens amarradas e também nos tira da narrativa das cabeças falantes, como nós, que estamos falando agora. É pouco dramático! Trabalhar com o quadrinho, esse é um recurso que nos joga direto na ação, e fica mais fácil visualizar aquilo que se passou.

Tânia Sarmento-Pantoja - Quando eu assisti o documentário eu lembrei do recurso da animação em outros filmes sobre a ditadura, como o "Infância Clandestina", que é um filme de ficção, totalmente envolvido com o tema da ditadura. Um documentário brasileiro chamado 
"Labirinto de papel”, muito concentrado no uso da animação, nesse sentido o teu documentário estabelece um diálogo muito interessante e positivo, na minha opinião com outras narrativas cinematográficas também direcionadas a essa temática.

Augusto Sarmento-Pantoja - Falando um pouco da questão mais técnica, sobre a recuperação da memória. Isa, a gente observa que o filme nos traz um conjunto representativo de imagens de arquivo, além de todo esse processo de gravar com o Carlos Eugênio em várias temporalidades. Você falou que são oito anos de produção, uma temporalidade bastante longa, você tem gravações em diferentes momentos, como foi essa seleção e constituição dessas temporalidades no filme?

Isa Albuquerque - Olha! Nós não precisaríamos de oito anos para realizar esse filme, se tivéssemos os recursos financeiros em mão. O tempo foi determinado pelo processo criativo, poderia ter resultado em um ano, dois, no máximo. Mas há a aprovação das etapas no processo de produção através das leis de incentivo, pois o empresariado não é muito simpático a esse tema, o que nos limita ao financiamento institucional da ANCINE, nosso instituto de cinema e fotografia aqui no Brasil. Passei muitos anos para conseguir um primeiro recurso para rodar o filme, rodei em 2012 e, depois, eu tive um grande problema para conseguir recurso para a produção complementar e depois para a finalização. Assim, eu recorri aos editais! Grande parte dessa luta, que é uma luta diária, foi para obter recursos. E quando você percebe, já se passaram aí anos, dois anos, por exemplo, tentando liberar um recurso que foi ganho em 2018. O mesmo aconteceu com todas as etapas, e nós tínhamos o governo de esquerda no poder. Estamos vivendo essa transposição de regime, de um governo de esquerda para um governo de extrema-direita e as dificuldades que nós tínhamos não eram tão diferentes, porque havia sempre alguém para ler o nosso projeto e dizer que não era um projeto comercial e diziam que tínhamos uma fatia de público, um nicho de público a atender, então, não interessaria aquele comando, aquele concurso, aquela agência! E trabalhar com uma narrativa de resgate da memória... enfim... muitos pareceres foram feitos com esse tipo de conteúdo e que atrasaram a nossa produção. Agora, os arquivos! Quando finalmente consegui completar o recurso de finalização, eu tive um grande colaborador, o cineasta Sílvio Da-Rin. Ele tinha um acervo reunido da ditadura militar e ele me cedeu estes arquivos. Eu tenho muita gratidão a ele e ao Roberto Chaim, que é outro cineasta, também foi de uma 
solidariedade imensa. Ele havia realizado o "Cidadão Boilesen”, personagem que cruzou a vida do Clemente e contra quem o Clemente também tem uma história de execução. O Chaim nos trouxe boa parte desses arquivos e imagens. Para além disso, eu estive pessoalmente levantando arquivos em uma instituição no Rio de Janeiro chamada Arquivo Nacional. Lá eu passei um ou dois meses levantando boa parte dos arquivos que estão lá. O grande segredo de um bom documentário é você conhecer bem seu material de arquivo, que precisa ser muito bem revisado! Não necessariamente precisa de anos para isso, nossa dificuldade com a produção, sem dúvida, não foi de reunir esse material, foi de disponibilizar recursos necessários para a produção desse material. Produção é um cheque na mão, gente! Não se consegue fazer nada, graciosamente cinema! E cinema é um mecanismo caro de produzir. E esse é um filme absolutamente barato, é um filme de baixo orçamento. Certo, que um baixo orçamento, é sempre grande para uma pessoa física, eu sou uma pessoa jurídica também, mas meu PJ também está sofrendo nas mãos desse desgoverno que está aí. É realmente bastante complicado, há alguns anos, fazer cinema no Brasil!

Augusto Sarmento-Pantoja - Vamos agora a uma coisa que você comentou dobre "Cidadão Boilesen". Na minha tese de doutorado e falo sobre esse filme, falo a partir de um conceito que eu levanto sobre o formato do documentário. Eu analiso que existem dois tipos de documentário performático, um heroicizante e outro reflexivo. Eu observo o teu filme exatamente nessa formulação reflexiva. O Clemente teria tudo para ser tratado apenas no âmbito da heroicização, e você traz para o filme uma reflexão sobre essa figura do Clemente, tratando ele enquanto um Carlos Eugênio e um Carlos Eugênio enquanto Clemente. Temos a história de Carlos Eugênio, os questionamentos, as contradições. Isso, para mim, é muito importante. Porque faz parte do processo da constituição da teoria do cinema, da teoria do documentário observar que há necessidade de fazer uma modificação de escopo sobre a questão da ditadura. É preciso trazer os heróis, mas é muito mais importante do que trazer os heróis, é importante fazer a reflexão sobre tudo o que aconteceu na história do Brasil e história no modo geral. E você fez isso, era o tratamento que você queria dar ao filme?

Isa Albuquerque - Olha! Eu sempre persigo a subjetividade do meu personagem, da pessoa que eu estou transformando em objeto, de tudo, ali no filme. Então, a subjetividade que determina a pessoa, o que há de pessoal nesse personagem. Filmar a subjetividade para mim 
é o primeiro plano. Se você observar também, eu procurei não trazer o depoimento, que é o que seria previsível, dos antagonistas da história, os militares, etc., eles já têm muita voz, eu preferi encontrar controvérsias dentro das próprias forças que estavam ali, dispostas a falar desse passado, dentro do próprio Carlos Eugênio. Meu objetivo foi trabalhar com essa reflexão interior do Carlos Eugênio. Era uma pessoa como ele era! Como ele passou por uma análise durante muitos anos! Verbalizar suas próprias inquietações não foi um processo difícil para ele, foi um processo doloroso como sempre é, mas também um processo fácil de verbalizar. Eu acho que o processo mais difícil dele foi expor realmente o episódio de execução do Márcio Toledo, mas eu, ciente disso, fui trabalhando em diversas etapas da vida dele, até que conseguiu verbalizar bem esse momento.

Sim! eu prefiro um documentário de cunho reflexivo, de reflexões. Apesar de ser um documentário de ações, apesar de estarmos tratando de uma espécie de herói da esquerda, nós estamos aí com um personagem que diz mais que os outros, agiu mais que os demais, revelou mais que a maioria. Um grande personagem! Nós precisávamos também da sua própria controvérsia para fundamentar bem esse documentário. Em busca dessas contradições, dessa controvérsia, eu procurei estar atenta ao longo da captação e montagem do filme. Tive também uma grande aliada que foi a Jordana Berg, que é a nossa montadora. Que soube me ajudar muito na organização dessas ideias e que foram trazidas da captação das imagens. Nós fizemos um amplo material de quase 50 horas de gravação, entre Rio de Janeiro, São Paulo, Paris. Conseguimos, até por ter tido esse processo de maturação. Talvez, tenha sido necessário todo esse movimento, que se estendeu por tanto tempo, porque eu pude captar vários Carlos Eugênio, em diferentes fases da vida dele. Na verdade, são oito anos! Desses oito anos os últimos dois foram vividos em busca do recurso para o lançamento, mas foi preciso trabalhar tanto tempo, comermos algum sal juntos, não é Maria Cláudia! E vivermos algumas dificuldades mesmo. Lutas do próprio cinema para chegar a esse resultado. Acho que foi muito produtivo. Para mim, foi um grande amigo também. Fiquei muito amiga da casa de Maria Cláudia. São decisões para uma vida: a aquisições de amizades, de afeto, de carinho... estamos juntas nessa luta! Agora, é para o lançamento do filme e também para outros projetos que a gente faz. Nada foi perdido, tudo foi realmente... Eu só quero ir mudando de fase. Acho que agora o fundamental é trabalhar e realizar esse lançamento $e$ tratar dos projetos a frente. 